\title{
RAYMOND DE VIEUSSENS ON MITRAL STENOSIS
}

\author{
BY \\ C. E. KELLETT \\ From the Newcastle General Hospital \\ Received November 15, 1958
}

Mitral stenosis, though noted in 1669 by John Mayow (1640-79), was more fully described by Raymond De Vieussens (1641-1716) who also noticed the character of the pulse (Rolleston, 1928). Major (1932) devoted a paper to De Vieussens and his Treatise on the Heart and reproduced, together with one engraving, nearly the whole of his lengthy account in his Classic Descriptions of Disease. Herrick (1942) in A Short History of Cardiology devotes two pages to his work on mitral stenosis and aortic regurgitation. It is possible, nevertheless, that De Vieussens, who devoted so much thought to this case, might feel that he has not been fully reported, that after all his conclusions have been in part omitted and only the least important of three plates with which he illustrated the case reproduced. Herein lies my justification for mentioning him to you, for by a curious chance the part of his work omitted has, as a result of operations recently designed to improve the circulation in the heart, acquired a new significance.

I have dealt elsewhere in detail with De Vieussens' life and so will merely remind you that he was born in 1641 and died in 1716, barely a year after the death of Louis XIV, whose tragic and splendid reign forms the background to the whole of his life. In 1688, three years after the publication of his Neurographia, their paths crossed. He was introduced to the King, who settled on him an annual pension of 1000 livres, as a reward and as an encouragement to further research. No conditions were attached to this award, which compares favourably with the 1500 livres a year paid to the very distinguished pensionaries of the newly formed Academie des Sciences. They were required to give all their time to the academy, while De Vieussens seems to have been left free to do whatever he wished and remained actively engaged in practice until the end of his life. Possibly this is why to subsequent anatomists, such as Cole (1921), his experiments have appeared amateurish and slipshod in the extreme. On the other hand, work done during the past few years does suggest that many anatomists have in the past been unduly conservative in their outlook, and that many anastomoses they dismissed as being due to artefact have a very real existence.

You will recall how, on November 8, 1705, Thomas D'Assis was, at his own request, admitted to the hospital of St. Eloi, at Montpellier. This was the time of Blenheim and Ramillies and of the loss of Gibraltar and Barcelona, a time of extreme financial stringency, and, despite heavy taxation, of government insolvency. D'Assis had come from Paris and, like many of his countrymen, was destitute. He was admitted under Deidier, the physician in charge, De Vieussens' son-inlaw, and, at his request, De Vieussens, then 64, visited him. 'I found him,' he writes, 'lying propped up in bed, his head held high; he seemed to have great difficulty in breathing and his heart was troubled by violent palpitation. His pulse appeared very small, feeble and altogether irregular. His lips were the colour of lead and his eyes sunken; his legs and thighs were swollen, and cold rather than hot.' De Vieussens gave a poor prognosis. He added that the violence of the palpitation of the heart and the nature of the symptoms associated with it were such as to convince him that the malady of this young man was due to an actual change, the nature of which eluded him, in the tissues of this organ.

A week later the patient died and on the following day, November 16, De Vieussens himself 440 
opened the body in the presence of his son-in-law and several medical students. On removing the sternum they found that the cavity of the chest was filled with a yellowish serous exudate, and that the lungs were extraordinarily large and soft, because all of its tissues were soaked in a watery lymphatic juice. He then pulled out the heart, with the larger vessels attached to it, from the cavity of the chest in order to examine it in detail. Its size was extraordinary, well nigh that of an

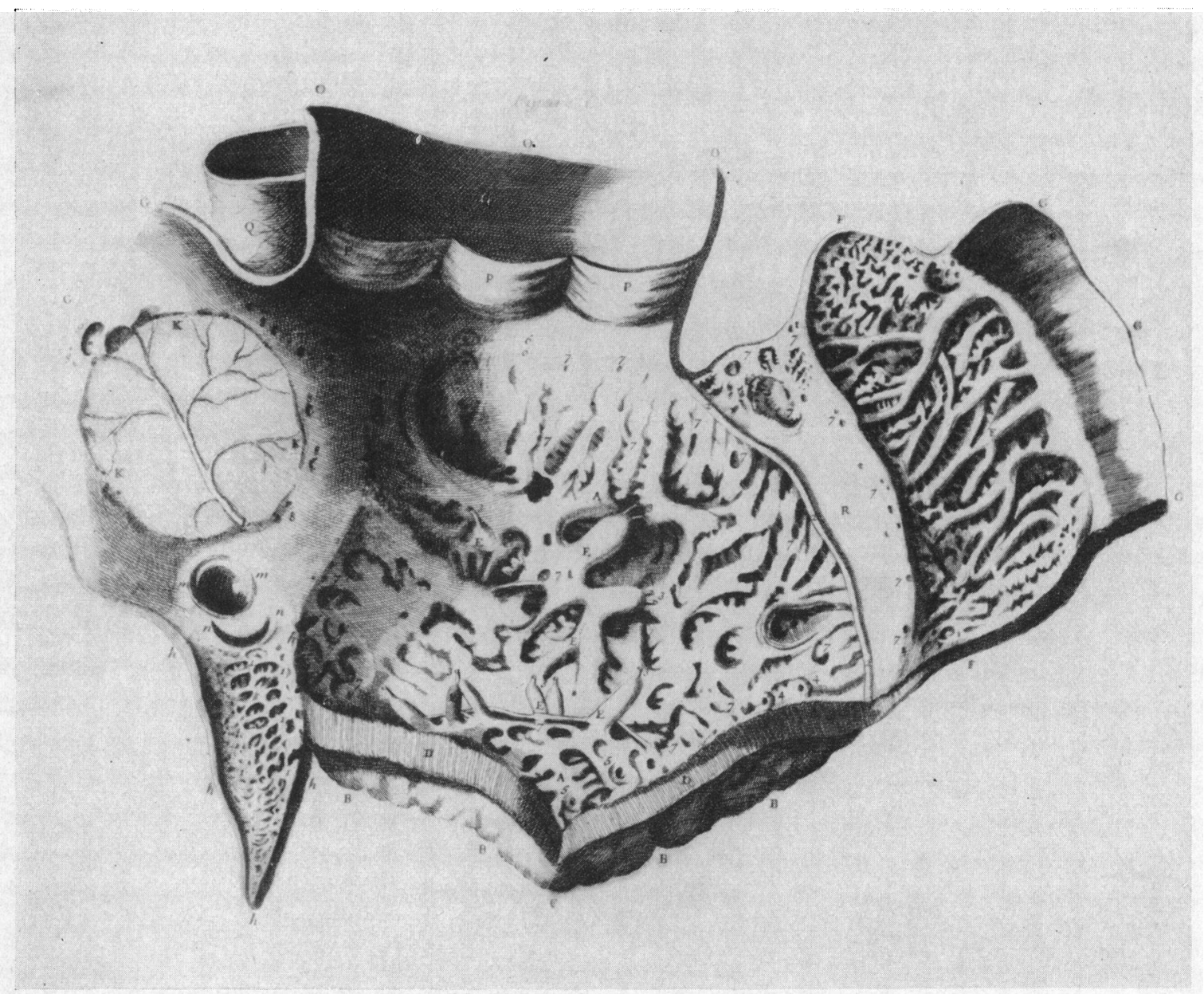

This reproduction of De Vieussens' Plate XII illustrates the right ventricle and auricle of Thomas D'Assis, from which the tricuspid valve has been removed so as to be able to show the common openings normally concealed by it.

AA The right ventricle opened out.

FFF The extraordinarily dilated right auricle. One should note that the crypts have become excessively large and that the bundles of muscles that bound them (musculi pectinati) have hypertrophied and the mouths of the common openings stretched to an extraordinary degree.

GGGGGG The sinus venarum.

hhhhh The portion of the same, which in the undissected specimens is united to and part of the posterior part of the right auricle in which the common openings marked by nine 1's have been dilated to an excessive degree.

$\mathrm{mm} \quad$ The unduly dilated opening of the superior coronary vein.

$\mathrm{nn} \quad$ The valve of this.

44 The margins of the mouths of two common openings which act as valves.

5-10 Different examples of these common openings. 
ox. The pulmonary veins and all their branches were over-dilated and the cavity of the right ventricle and of the right auricle had become excessively large. These features are shown in detail on his plate XII, which is here reproduced, together with part of the long explanation attached to it, and you will note the care with which the enlarged common openings are portrayed.

De Vieussens had devoted great care to the preparation of these plates. The drawings were made in Montpellier by Lason in the course of the actual dissections and they were subsequently taken by him to Paris to be engraved under his supervision by Simonneau, who was, he tells us, one of the foremost engravers of his time. The book was approved for publication in 1709 but did not appear until 1715, within one year of his death. It was probably published at his own expense and is in a sense his testament, as is clearly implied in the preface, in which he dwells for the last time on his contributions to medicine and enumerates his discoveries. The most important of these from his point of view would seem to have been the detection of these common openings. We now know that there is approximately one capillary to every muscle fibre in the heart. De Vieussens thought that this capillary and the muscle fibre were the same thing and refers to them as his "fleshy ducts" or "conduits charneux." He demonstrated that the blood in the coronary vessels which supplies the exterior surface of the heart passes to the coronary veins through an infinite number of these fleshy ducts, or as we would say capillaries, and he noted that the branches of the coronary vessels, which pass down to the thickness of the walls of the ventricles of the heart and to the partition between the two ventricles, were not accompanied by any veins. 'I concluded, therefore,' he tells us, 'that the blood they bore must with each contraction of the heart be discharged into the ventricles. At that time I was unaware of the particular path taken but, he adds, I looked for this with such care that I made my fourth discovery, namely of a large number of conduits in the inner surface not only of the ventricles but of the auricles. I made my fifth discovery when I found that each conduit, which was lined with a very fine and porous membrane, was common to several fleshy ducts that led into it, hence my name, common openings, and my sixth when I found that in each ventricle little folds acted as valves to these openings; stretching as the heart dilated in diastole and closing them, shrinking and leaving them open in systole.' The openings into the auricles were without valves but were instead, De Vieussens thought, covered with a very fine and porous membrane, through which the blood filtered, and here it would seem he spoke as a true Cartesian and disciple of de Regis, rather than as an unbiased observer. Indeed this aspect of his discovery looms large in his first account written in the form of a letter dated March 29, 1705, and published as a small octavo the following year.

Recent work has fully confirmed De Vieussens' conception of two modes of venous drainage of the heart; the superficial system, which opens into the right auricle and consists of the anterior cardiac veins of the coronary sinus, together with associated veins emptying near its mouth, and a deeper system of veins which communicates directly with the heart chambers by a series of so-called common openings. There is still much confusion as to the effect of systole and diastole on this aspect of the coronary circulation and De Vieussens' view of a valvular control is unconfirmed.

We are now in a better position to share in De Vieussens' excitement when he opened the right ventricle and noticed that the common openings in this ventricle had become so dilated and the membranes that covered them so stretched that they freely allowed the blood to pass. The same had occurred in the auricle. When, therefore, he squeezed with his fingers the wall of the right ventricle or that of the auricle, blood poured from these holes. 'There is then,' he said, 'no reason for doubting that these openings are present in the hearts of all men, such as I have described.'

As he proceeded with the dissection he noted that the vena cava had become grossly dilated and that the mouths of two little coronary veins he had described, opening directly into it, had also become dilated. The changes in the pulmonary veins and in the left auricle were even greater. At this point, you will remember, he noticed that the mouth of the left ventricle appeared very small and had an oval oblong shape. In searching for the cause of such a surprising fact, he discovered that the mitral valve of this ventricle was really bony: he realised that, as they had become hardened, 
the cusps had become thickened and rough enough to cause a severe narrowing of the lumen, presenting a picture such as is shown in the figure usually reproduced.

Having carefully examined the trunk of the pulmonary vein, he opened the left ventricle and noticed once more that the substance of the mitral valve was ossified and that there had been a great diminution and indeed change in the natural shape of its lumen. He furthermore noticed that the bundles of muscle fibres, which formed the sides of the fossa of this ventricle, were either smaller than usual because they did not receive as much blood as they had been accustomed to prior to the change in the mitral valve, or not receiving any at all had become pale and taken the form of small tendinous ligaments, to all intents and purposes like those of the mitral valve.

De Vieussens concluded that the opening to the left ventricle having become so very much narrowed, and the margin of this opening having lost all its natural suppleness, blood could no longer enter as freely and as abundantly as it should have done into the cavity of this ventricle. To begin with, the circulation was embarrassed and the blood began to dilate to an extraordinary extent the trunk of the pulmonary vein because it stayed there too long and was accumulating in excess. But the blood had no sooner begun to stay too long in the trunk of this vessel when it delayed the flow of all the vessels of the lungs. As a result the branches of the pulmonary vein and artery throughout the tissue of this organ were always engorged with blood and as a result so dilated that they compressed to some extent the alveoli, thus preventing air from entering or leaving them freely. That was why, he added, he thought the patient always breathed with such difficulty. Since the blood had thickened considerably in the lungs as a result of this long stay in the pulmonary vessels a part of its serum separated little by little and fell into the cavity of the chest.

It was possible then, De Vieussens felt, to relate D'Assis' symptoms to these pathological findings. 'I have,' he wrote, 'mentioned that to begin with the circulation of the blood was embarrassed by the excessive narrowing of the opening into the left ventricle and began, therefore, to be held up in the trunk of the pulmonary vein, so delaying the flow of the blood in all the vessels of the lungs. But, I should have gone further, for at the same time it impeded the constant flow of blood from the vena cava, the coronary veins and innominate veins to the right auricle and ventricle. That is why that portion of the vena cava in which this, and the other vessels I have mentioned, terminate was always engorged with blood. As a result, it was unduly dilated, both because of the excessive quantity of the blood and because of the blood's pulsation, and this so augmented its elastic force that it obliged it to contract with considerable violence. Therefore,' he adds, for he felt that the heart beat was initiated by the distension of this part of the vena cava, 'one must not be surprised that Thomas D'Assis was troubled by a violent palpitation of the heart during the course of the malady from which he died. On the other hand, the small volume and feeble quality and irregularity of his pulse arose from the too small quantity of blood that the left ventricle furnished to the aorta and from the little force with which the ventricle pushed it into the cavity of this artery and from the irregularity of its contractions. With regard to the leaden colour of the lips and the lack of lustre in the eyes, the swelling of the legs and thighs, and the diminution in their natural heat, I would say,' he concludes, 'that all these symptoms are the result of the same cause, namely an upset in the circulation of the blood and its constituents, as will be easily understood by anyone who has some knowledge of the economy of the human body.'

I do not wish to-day to dwell upon the skill with which De Vieussens related his pathological findings to the clinical picture presented by his patient. I am concerned rather with the significance of his finding that the so-called common openings are grossly dilated in this condition. So far as I am aware, no one has actually confirmed these findings but, if I may be guided by my own limited experience, this is an accurate observation, and I believe that the very remarkable changes that may take place in the pressure in the right auricle and ventricle, as well as the left auricle, are calculated to bring about the changes he has described. So gross a venous engorgement of the heart is not easily reproduced experimentally but the operation recently devised by Fauteux (1946) which involves ligation of the great cardiac vein, is calculated to produce such an effect. Furthermore, if we believe that this third circulation described by De Vieussens is controlled by a valvular system, 
such as he thought he had detected, which was in this case rendered nugatory by the distension of the common openings, then there are grounds for thinking that the operation devised by Beck (1948) is more likely to produce the sort of changes that had been noticed in the heart of Thomas D'Assis. This operation involves placing a free vein graft between the aorta and the coronary sinus or a direct anastomosis between these two structures. The second stage of this operation is done two or three weeks later and consists of partial occlusion of the coronary sinus as it enters the right auricle. This partial occlusion raises the pressure of blood in the sinus and produces retrograde flow.

Now, as you are well aware, both these operations are designed to relieve or rather correct cardiac infarction and it may at this stage occur to many of you that cardiac infarction is a remarkably rare complication of mitral stenosis. I think it is probable, therefore, that De Vieussens' description of his findings in the case of Thomas D'Assis has never really been appreciated at its true worth, for not only did he describe changes in the systemic and pulmonary circulation arising from the presence of this mitral stenosis, but also described and illustrated with great care the changes that may take place in these vessels within the heart itself, which he was the first to discover.

\section{REFERENCES}

Beck, C. S. (1948). Ann. Surg., 128, 854.

Fauteux, M. (1946). Amer. Heart J., 31, 260.

Cole, F. J. (1921). The History of Anatomical Injections. Studies in the History and Method of Science. Ed. Charles Singer. Oxford. Vol. II. pp. 285-343.

Herrick, J. B. (1942). A Short History of Cardiology. C. C. Thomas, Springfield and Baltimore.

Kellett, C. E. (1942). Ann. Med. Hist., New York, 3rd Series, 4, 31.

Lower, R. (1669). Early Science in Oxford. T. Gunther. Vol. IX. De Corde, by Richard Lower. Translated by K. J. Franklin. Oxford, 1932.

Major, R. H. (1932). Ann. Med. Hist., New York, N.S. 4, 147.

Mayow, J. (1674). Medico-Physical Works. Alembic Club Reprints No. 17, Edinburgh, 1907.

Rolleston, H. (1928). The Harveian Oration. Cambridge University Press.

De Vieussens, R. (1706). Nouvelles Découvertes sur le Coeur. Laurent d'Houry, Paris.

- (1715). Traité Nouveau de la Structure et des Causes du Mouvement naturel du Coeur. pp. 102-106, Toulouse.

- (1774). Histoire des Maladies Internes. Vol. 2, pp. 177-180, Toulouse. 